University of Nebraska - Lincoln

DigitalCommons@University of Nebraska - Lincoln

November 2004

\title{
Using developmental, cognitive, and neuroscience approaches to understand executive control in young children
}

\author{
K. A. Espy \\ University of Nebraska-Lincoln, kespy2@unl.edu
}

Follow this and additional works at: https://digitalcommons.unl.edu/dcnlfacpub

Part of the Neurosciences Commons

Espy, K. A., "Using developmental, cognitive, and neuroscience approaches to understand executive control in young children" (2004). Developmental Cognitive Neuroscience Laboratory - Faculty and Staff Publications. 10.

https://digitalcommons.unl.edu/dcnlfacpub/10

This Article is brought to you for free and open access by the Developmental Cognitive Neuroscience Laboratory at DigitalCommons@University of Nebraska - Lincoln. It has been accepted for inclusion in Developmental Cognitive Neuroscience Laboratory - Faculty and Staff Publications by an authorized administrator of DigitalCommons@University of Nebraska - Lincoln. 


\title{
Using Developmental, Cognitive, and Neuroscience Approaches to Understand Executive Control in Young Children
}

\author{
Kimberly Andrews Espy \\ Department of Family and Community Medicine \\ Southern Illinois University School of Medicine
}

\begin{abstract}
The 7 articles in this special issue address the nature of executive control in young children. Executive control is framed in a developmental context, where the unique aspects of cognition in this age range are considered. The set of articles demonstrates the multidisciplinary approaches to study cognition in young children that includes application of cognitive, neuroscience, and developmental paradigms in typically developing youngsters, as well as those affected by clinical conditions, such as traumatic brain injury, exposure to low levels of lead in the environment, and prematurity. Although much work remains to be done, these study results are illustrative of the dynamic work in this exciting developmental period.
\end{abstract}

At first glance, it would appear to be an oxymoron to study executive control in young children between ages 2 and 6 years. By definition, children of this age act "in the moment"- that is, they are impulsive, repetitive, inattentive, and cannot keep salient information in mind. It is precisely this kind of unmodulated behavior that is difficult to label executive, a term usually reserved for purposeful, planned, goal-directed action. In fact, the behavior of preschoolers resembles that of Phineas Gage, EVR (Eslinger \& Damasio, 1985), and other famous patients with circumscribed lesions to the prefrontal cortex and related systems. Like many things with preschoolers, the first blush view may not be the most accurate representation.

Besides the remarkable "dysexecutive" behavioral presentation of young children, there also have been scientific impediments to considering executive control

Requests for reprints should be sent to Kimberly Andrews Espy, Department of Family and Community Medicine, MC 6503, Southern Illinois University School of Medicine, 600 Agriculture Dr., Carbondale, IL 62901-6503. E-mail: kespy@siumed.edu 
in young children. Pioneering neuropsychologists, such as Brenda Milner (1963), demonstrated such compelling dissociations between knowledge and action in patients with prefrontal damage on the Wisconsin Card Sorting test (WCST; Heaton, Chelune, Talley, Kay, \& Curtiss, 1993) that WCST performance became the sine qua non for executive functioning. Following this metaphor to its conclusion leads to a teleological error-young children cannot have executive abilities because they cannot complete the WCST. The emergence of pediatric neuropsychology has been critical in forcing the consideration of childhood cognition in a developmental context - that is, children are quantitatively, and qualitatively, different from adults - precisely because abilities are in an active state of change (e.g., Dennis, 1987; Fletcher \& Taylor, 1984). Developmentalists consistently have shown that preschoolers generally do not suffer from a lack of abilities, but rather from the ability to deploy these abilities in particular contexts (e.g., Flavell, 1999) that is, they lack basic metacognitive awareness of when, and how, to apply their knowledge and to deploy particular strategies effectively.

With this context in mind, the study of executive control in young children has burgeoned recently - driven by the confluence of several factors. First, several psychiatric and neurodevelopmental conditions become prominent in the preschool age range, in particular, Attention Deficit Hyperactivity Disorder. Therefore, it might be useful to be able to better identify children at risk for such disorders earlier in development, so as to reduce morbidity severity. In a related vein, understanding the genesis of the cognitive underpinnings of a disorder will shed light on the complex interplay among cognitive processes, development, and the social environment, which dynamically shape the pathways to adverse outcome later in life.

Second, paralleling these developments was the application of basic neuroscience techniques to elucidate brain-behavior relations in primates. Goldman-Rakic (1987) elegantly demonstrated that various manipulations to the dorsolateral prefrontal cortex fundamentally alter goal-directed behavior of the monkey, with outcome varying with respect to when during development these lesions occurred (Goldman, 1974). These monkeys demonstrated the same repetitive, perseverative behavior as that shown by patients with prefrontal damage evidence. Given the context of the limitations of primate cognition, perhaps these neuroscience tasks could be adapted for use with humans, with the added advantage of a more direct link to brain function than was available with traditional, standardized clinical instruments. Diamond (1985) first pioneered the application of such paradigms with infants, demonstrating striking parallels between infant search behavior and that of prefrontally lesioned monkeys. Such studies opened the door to the application of various paradigms from different disciplines to study executive control in preschool children. Just as Fletcher stressed in his 1996 Developmental Neuropsychology special series, "Executive Functions in Children," "the goal is to use cognitive tasks to understand the nature of brain function in children and brain dysfunction in CNS disorders specific to children" (p. 3), not to rely excessively on 
adult paradigms, findings, or principles. Children are not little adults, nor are preschoolers little children. Understanding brain behavior relations in the very young requires the use of innovative paradigms from multiple disciplines that capitalize on the unique, developmentally salient interests of this age range, taking into account the real limitations in verbal and motoric facility and in the variable attention span (e.g., Espy, 1997; Espy, Kaufmann, Glisky, \& McDiarmid, 2001).

This historical context is the backdrop of this special issue. The seven articles demonstrate different measurement techniques that can be used to better understand the nature and organization of executive control in young children. Smidts, Jacobs, and Anderson (this issue) present their findings on the development of a concept generation task for use in early childhood. The task has its origins in adult neuropsychology, but Smidts et al. use a decidedly developmental approach for test development. Isquith, Gioia, and Espy (this issue), on the other hand, discuss the adaptation of a childhood paper-and-pencil instrument that can be completed by parents or teachers to assess divergent executive abilities. Rennie, Bull, and Diamond (this issue) use experimental methods to manipulate salient task demands to explicate the cognitive processes that underlie performance on the Dimensional Change Card Sort (DCCS) task (Zelazo, Reznick, \& Pinion, 1995), a task used in the developmental psychology literature to demonstrate the development of sorting behavior. Finally, Senn, Espy, and Kaufmann (this issue) demonstrate the use of quantitative statistical techniques to investigate different models of executive control organization through systematically comparing structural models that are premised on tasks adapted from neuroscience, cognitive, and developmental disciplines. These studies share careful operationalization of the executive process under study and draw on cognitive or neuroscience models or both (Smidts et al., Rennie et al., and Senn et al.), or use a more empirical approach through psychometrics (Isquith et al., Senn et al., and Espy, McDiarmid, Cwik, Stalets, Hamby, \& Senn, this issue).

Another purpose of the selected articles is to highlight the central role of executive control in outcomes that matter in the proximal day-to-day lives of young children. Although brain-behavior relations are interesting in their own right, and certainly important scientifically, it is the behavior-behavior relations (Fletcher \& Taylor, 1984), that is, relations between cognitive processes and outcomes, such as behavior or academic achievement, that concern parents, educators, and policymakers. Isquith et al. (this issue) focus on behaviors in the everyday context, as conceived by both parents and teachers. Espy et al. (this issue) relate differing executive processes to early proficiency in mathematics, as measured by a widely used, standardized clinical instrument. These studies represent a first step in understanding the complex dynamics that underlie more proximal outcomes, such as behavior and academic achievement, in young children.

In a related vein, the final goal was to illustrate how executive control is altered by various CNS disorders of childhood, namely traumatic brain injury in the Ew- 
ing-Cobbs, Prasad, Landry, Kramer, and DeLeon article (this issue), and exposure to low levels of lead in the environment in the Canfield, Gendle, and Cory-Slechta article (this issue). In both articles, the paradigms used to assess executive control draw heavily from developmental cognitive neuroscience fields to effectively illustrate substantive variations in outcome. Despite the clinical orientation of these articles, the specific tasks chosen are driven by empirical theory. Clearly, even in investigations with young children, the time is past for the practice of administering a large battery of standardized tests and looking for differences post hoc. Isquith et al. (this issue) take a different tack, empirically contrasting the ratings of everyday executive behavior among children with various clinical conditions using analysis of scale profiles.

These seven articles represent a sampling of the exciting findings that are beginning to emerge from studies of executive control in young children. Clearly, much work remains to be done to truly explicate the developmental trajectories of the differing facets of executive control in this age range, with the next logical step being the use of longitudinal designs. One cautionary note: Because of the unique assessment methods used to assess executive control in young children, it will be necessary to formally establish the relation to subsequent abilities at school age and beyond. It may appear, for example, that the executive abilities required to complete the DCCS task at age 4 are isomorphic with those required for adequate performance on the WCST at age 8 . In reality, the task demands and the organization of executive abilities may differ both qualitatively and quantitiatively, rendering a level of complexity that makes such relations less than intuitive and meriting careful study.

Although the studies here used empirical or strong theoretical justifications or both for task selection to test specific hypotheses, further refinement of the relations between executive tasks and executive constructs is necessary. Clearly, these complex tasks are multifactorial, that is, different abilities are required for smooth, purposeful, goal-directed behavior. What remains to be clarified is whether executive abilities are truly fractionated, or whether differing task demands engage a unitary executive control process - or some combination therein. In children, and particularly young children, where maturation is so rapid, the overlay of developmental change makes this issue more complicated. In the adult neuroimaging literature, it is clear that task characteristics, such as salience, novelty, reward, expectancy, affect the degree of frontal engagement (e.g., Barch et al., 1997; Casey et al., 2001; Petersen, van Mier, Fiez, \& Raichle, 1998; Rogers, Owen, Middleton, Williams, \& Pickard, 1999). In children, it is difficult to fully equate tasks with respect to these issues, posing unique challenges in the measurement of executive abilities in the developmental context.

Finally, there remain significant barriers to determining the true developmental brain representations of behavior in this age range. With the current scanning setups, young children are not suitable candidates to participate in functional mag- 
netic resonance imaging (fMRI) studies that have expanded so elegantly this knowledge base in adults and even in children. High-density event-related (brain) potential recordings may offer the best hope currently, although the spatial precision is not ideal, particularly considering that fMRI findings show that cognitive functions may be subserved by more diffuse brain areas in school-age children in comparison to adults (e.g., Casey et al., 1995). Nonetheless, these seven articles represent real advances in explicating the nature of executive control in young children.

\section{ACKNOWLEDGMENTS}

This research was supported, in part, by the Pediatric Neuropsychology/Developmental Cognitive Neuroscience Award from the Rita Rudel Foundation; a research grant from the Blowitz-Ridgeway Foundation; and the Special Research Program award from the Southern Illinois University Office of Research Development and Administration.

\section{REFERENCES}

Barch, D., Braver, T., Nystrom, L., Forman, S., Noll, D., \& Cohen, J. (1997). Dissociating working memory from task difficulty in human prefrontal cortex. Neuropsychologia, 35, 1373-1380.

Canfield, R. L., Gendle, M. H., \& Cory-Slechta, D. A. (2004/this issue). Impaired neuropsychological functioning in lead-exposed children. Developmental Neuropsychology, 26, 513-540.

Casey, B. J., Cohen, J., Jezzard. P., Turner, R., Noll, D. C., Trainor, R. J., et al. (1995). Activation of the prefrontal cortex in children during a non-spatial working memory task with functional MRI. Neuroimage, 2, 221-229.

Casey, B. J., Forman, S., Franzen, P., Berkowitz, A., Braver, T., Nystrom, L, et al. (2001). Sensitivity of prefrontal cortex to changes in target probability: A functional MRI study. Human Brain Mapping, 13, 26-33.

Dennis, M. (1987). Using language to parse the young damaged brain. Journal of Clinical and Experimental Neuropsychology, 9, 723-753.

Diamond, A. (1985). Development of the ability to use recall to guide action, as indicated by infants' performance on AB. Child Development, 56, 868-883.

Eslinger, P. J., \& Damasio, A. R. (1985). Severe disturbance of higher cognition after bilateral frontal lobe ablation: Patient EVR. Neurology, 35, 1731-1741.

Espy, K. A. (1997). The shape school: Assessing executive function in preschool children. Developmental Neuropsychology, 13, 495-499.

Espy, K. A., Kaufmann, P. M., Glisky, M. L., \& McDiarmid, M. D. (2001). New procedures to assess executive functions in preschool children. Clinical Neuropsychologist, 15, 46-58.

Espy, K. A., McDiarmid, M. M., Cwik, M. F., Stalets, M. M., Hamby, A., \& Senn, T. E. (2004/this issue). The contribution of executive functions to emergent mathematic skills in preschool children. Developmental Neuropsychology, 26, 465-486. 
Ewing-Cobbs, L., Prasad, M. R., Landry, S. H., Kramer, L., \& DeLeon, R. (2004/this issue). Executive functions following traumatic brain injury in young children: A preliminary analysis. Developmental Neuropsychology, 26, 487-512.

Flavell, J. H. (1999). Cognitive development: Children's knowledge about the mind. Anmual Review of Psychology, 50. 21-45.

Fletcher, J. M. (1996). Executive functions in children: Introduction to the special series. Developmental Neuropsychology, 12, 1-3.

Fletcher, J. M., \& Taylor, H. G. (1984). Neuropsychological approaches to children: Towards a developmental neuropsychology. Journal of Clinical Neuropsychology, 6, 39-56.

Goldman, P. S. (1974). An alternative to developmental plasticity: Heterology of CNS structures in infants and adults. In D. Stein, J. Rosen, \& N. Butters (Eds.), Plasticity and recovery of function in the central nervous system (pp. 149-174). New York: Academic.

Goldman-Rakic, P. S. (1987). Circuitry of primate prefrontal cortex and regulation of behavior by representational knowledge. In F. Plum \& V. Mountcastle (Eds.), Handbook of physiology (Vol. 5, pp. 373-417). Bethesda, MD: American Physiological Society.

Heaton, R. K., Chelune, G. J., Talley, J. L., Kay, G. G., \& Curtiss, G. (1993). Wisconsin Card Sorting Test manual. Odessa, FL: Psychological Assessment Resources.

Isquith, P. K., Gioia, G. A., \& Espy, K. A. (2004/this issue). Executive function in preschool children: Examination through everyday behavior. Developmental Neuropsychology, 26, 403-422.

Milner, B. (1963). Effects of different brain lesions on card sorting. Archives of Neurology, 9. 90-100.

Petersen, S., van Mier, H., Fiez, J., \& Raichle, M. (1998). The effects of practice on the functional anatomy of task performance. Proceedings of the National Academy of Sciences, 95, 853-860.

Rennie, D. A. C., Bull, R., \& Diamond, A. (2004/this issue). Executive functioning in preschoolers: Reducing the inhibitory demands of the Dimensional Change Card Sort Task. Developmental Neuropsychology, 26, 423-443.

Rogers, R., Owen, A., Middleton, H., Williams, E., \& Pickard, J. (1999). Choosing between small, likely rewards and large unlikely rewards activates inferior and orbital prefrontal cortex. Journal of Neuroscience, 19, 9029-9038.

Smidts, D. P., Jacobs, R., \& Anderson, V. (2004/this issue). The Object Classification Task for Children (OCTC): A measure of concept generation and mental flexibility in early childhood. Developmental Neuropsychology, 26, 385-401.

Senn, T. E., Espy, K. A., \& Kaufmann, P. M. (2004/this issue). Using path analysis to understand executive function organization in preschool children. Developmental Neuropsychology, 26, 445-464.

Zelazo, P. D., Reznick, J. S., \& Pinion, D. E. (1995). Response control and the execution of verbal roles. Developmental Psychology, 31, 508-517. 
Copyright of Developmental Neuropsychology is the property of Lawrence Erlbaum Associates and its content may not be copied or emailed to multiple sites or posted to a listserv without the copyright holder's express written permission. However, users may print, download, or email articles for individual use. 